\title{
Evaluation of Vector-Controlled Asynchronous Machines
}

\author{
Nihad M. Ameen ${ }^{1}$, Ammar S. Muhammed ${ }^{2}$ \\ ${ }^{I}$ Department of Communication Engineering -University of Technology, Baghdad, Iraq. \\ ${ }^{2}$ Department of Electrical Engineering, University of Technology, Baghdad, Iraq. \\ 30018@uotechnology.edu.iq,30156@uotechnology.edu.iq
}

\begin{abstract}
In this paper vector control with variable frequency drive used to apply speed control of a three-phase AC Asynchronous and induction machines. The flux and torque references used to obtain the current components. Proportional-Integral controllers are used to keeping the measured current components at their reference values. The stator voltage references are the output of the PI current controllers. High-performance with the smooth operation is obtained using the proposed method. The differences can be seen in behavior dynamic state. When the motor is rotating at full speed with a full load,it reaches good current waveforms very easily due to the independent PI control of torque and magnitude of flux. In high and sudden variations of the reference input, the direct command is more efficient and less demanding for the equipment. The expressions of the fundamental variables (speed, torque, flux) and equivalent phase circuit of the machine will be reviewed.
\end{abstract}

Index Terms - Vector Control, Asynchronous Machine, PI controller.

\section{INTRODUCTION}

Any motorization problem of an electric machine can be expressed in a simplified form by using input variables (voltage, current, frequency) and output variables (speed, torque, shaft angle) with variable load where the choice of motorization is made according to different criteria: performances, cost, maintenance and tuning [1,2]. The typical circuit established by analogy with the transformer where the frequency of the variables at the stator (primary) and at the rotor (secondary) are equal [3].

\section{MODEL ESTABLISHMENT}

The model is established using equations of the machine in the steady state considering that the machine is not saturated and the iron losses are not considered [4]. Figure (1) shows the common circuit with the transform ratio,

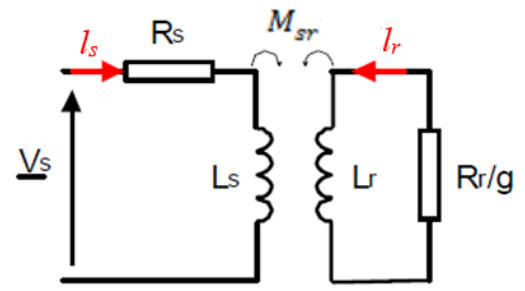

Fig. 1. THE TYPICAL CIRCUIT WITH THE TRANSFORM RATIO ERROR! REFERENCE SOURCE NOT FOUND.

Mesh current analysis produces:

$$
\underline{V_{s}}=R_{s} \underline{l_{s}}+j \omega_{s} \underline{l_{s}}+j \omega_{s} M_{s r} \underline{l_{r}}
$$




$$
0=\left(\frac{R_{r}}{g}\right) \underline{l_{r}}+j \omega_{s} L_{r} \underline{\operatorname{lr}} j \omega_{s} M_{s r} \underline{l_{s}}
$$

$V_{s}$ : RMS stator voltage by phase. $M_{s}$ : Cyclical mutual inductance. $L_{s}$ : Cyclical stator inductance $\left(l_{s}\right.$ : stator self-inductance). $L_{r}$ : Cyclical rotor inductance ( $l_{r}$ : rotor self-inductance). $\omega_{s}\left(\omega_{r}\right)$ : Angular frequency of the stator(rotor) variables. $R_{s}\left(R_{r}\right)$ : Resistance of a stator winding (rotor). $g$ : Slip.

The cyclical leakage inductances at the stator and the rotor with an equivalent circuit can be defined as shown in Figure (2).

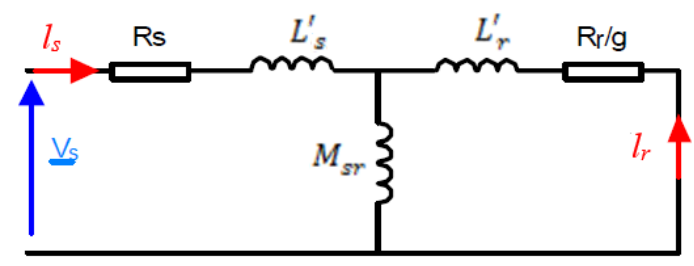

Fig. 2. The EQuivalent CiRCUIT WITH LEAKAGE INDUCTANCES [4].

It is possible to simplify the circuit by restoring the leakage inductances to the rotor or the stator. Circuit with leakage inductances situated in the rotor is shown in Figure (3-a) and the circuit with leakage inductances located at the stator is shown in Figure (3-b).
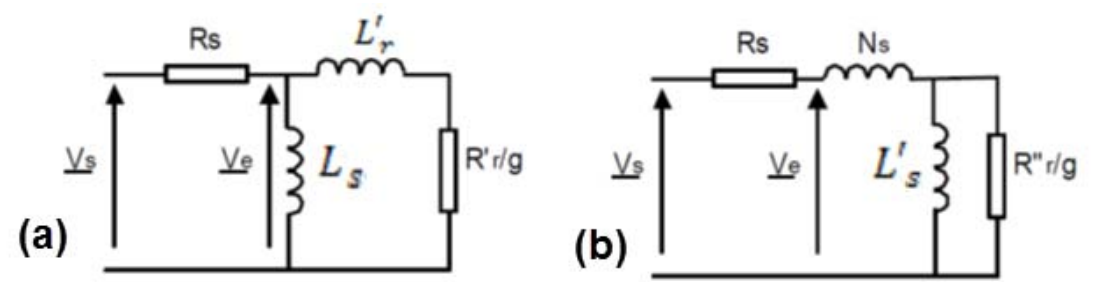

Fig. 3. EQUiVALENT CiRCUIT WITH LEAKAGE INDUCTANCES LOCATED AT THE A-ROTOR, B-STATOR.

The equation for the equivalent circuit with leakage inductances located at the rotor can be written as:

$$
\begin{gathered}
R_{r}^{\prime}=\left(\frac{L_{s}}{M_{s r}}\right)^{2} \cdot R_{r} \\
L_{r}^{\prime}=\left(\frac{L_{s}}{M_{s r}}\right)^{2} \cdot\left(1-\frac{M_{s r}{ }^{2}}{L_{s} L_{r}}\right) L_{r}=\sigma \cdot\left(\frac{L_{s}}{M_{s r}}\right)^{2} \cdot L_{r} \\
\sigma=1-\frac{M_{s r}{ }^{2}}{L_{s} L_{r}}
\end{gathered}
$$

The equation for the equivalent circuit with leakage inductances located at the stator can be written as [5]:

$$
\begin{aligned}
& R_{r}^{\prime}=\left(\frac{M_{s r}}{L_{r}}\right)^{2} \cdot R_{r} \\
& L_{r}^{\prime}=\frac{M_{s r}{ }^{2}}{L_{r}}
\end{aligned}
$$

\section{Torque in steady state}

In scalar control, the equalities show that the tuning variables of the torque are the rotor angular frequency $\omega_{r}$ and the flux $\Phi_{s}$ or $\Phi_{r}$. The expression of the electromagnetic torque is deduced by carrying out a power using the above models [6].

1- In function of the rotor flux:

$$
T_{e}=3 p \cdot \Phi_{r}^{2} \cdot \frac{\omega_{r}}{R_{r}}
$$


The 2-In function of the stator flux:

$$
T_{e}=3 p \cdot\left(\frac{M_{S r}}{L_{S}}\right)^{2} \Phi_{S}^{2} \cdot \frac{\frac{R_{r}}{\omega_{r}}}{\left(\frac{R_{r}}{\omega_{r}}\right)^{2}+\left(\sigma \cdot L_{r}\right)^{2}}
$$

For operation near synchronism, we consider that:

$$
\left(\frac{R_{r}}{\omega_{r}}\right)^{2} \gg\left(\sigma . L_{r}\right)^{2}
$$

And the relation can be written as:

$$
T_{e}=3 p \cdot\left(\frac{M_{s r}}{L_{s}}\right)^{2} \Phi_{S}^{2} \cdot \frac{\omega_{r}}{R_{r}}
$$

When the coupling is good, we can consider that:

$$
\frac{M_{s r}}{L_{s}} . \Phi_{s}=\Phi_{r}
$$

The principle of control of the electromagnetic torque by the flux-oriented method is based on knowledge of the dynamic model of the machine [6]. The choice of the Park model is commonly used because it simplifies the elaboration of control variables. This transform allows us to work in an equivalent two-phase system (in blue) instead of a three-phase system (in black) [7]. By applying this transform to the physical variables of the asynchronous machine (voltages, currents, and flux), the rotor and stator variables can be applied as shown in Figure (4).

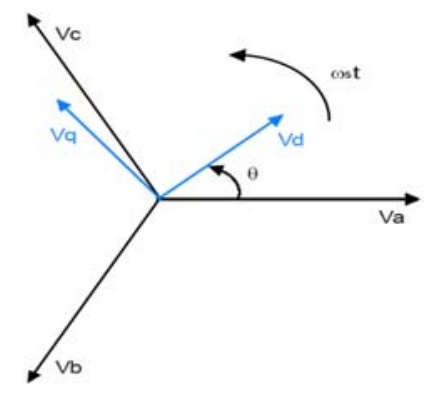

FIG. 4. EQUIVALENT TWO-PHASE SYSTEM.

When we apply this transform to the physical variables linked to the asynchronous machine the choice of the angle $\theta$ determines the choice of the working reference frame. In the case of a threephase asynchronous machine of the previous transform to the stator and rotor variables can be applied as shown in Figure (5-a) and Figure (5-b).
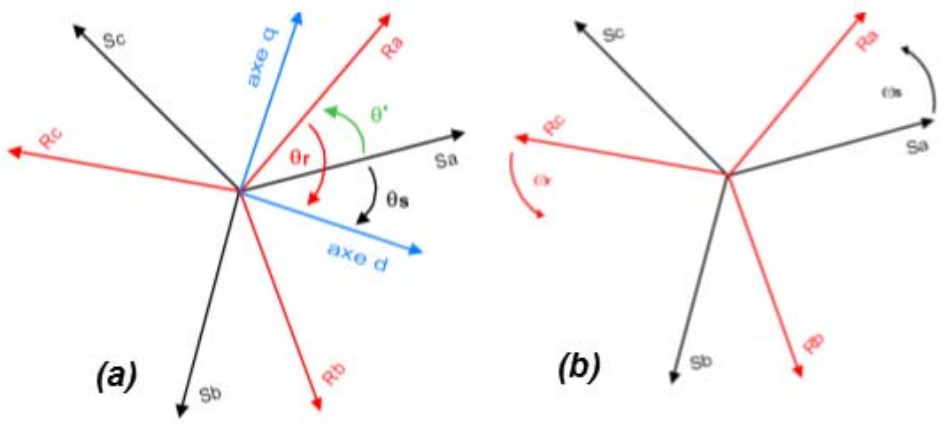

FIG. 5. TRANSFORM TO THE PHYSICAL VARIABLES OF THE A-ROTOR VARIABLES; B- STATOR VARIABLES [7].

In relation to the stator with $\omega^{\prime}=(1-g) \omega_{\mathrm{s}}$ the most common equivalent model in function of chosen reference frame when the dq coordinates are set in relation to the rotating field (or $\left.\omega_{s} / p\right)$ and 
therefore $\theta_{\mathrm{s}}=\omega_{\mathrm{t}}$ and $\theta_{\mathrm{r}}=\mathrm{g} \omega_{\mathrm{t}}$. This solution is very interesting for speed control because in the steady sinusoidal state the voltages $V_{d}$ and $V_{q}$ are constant [7]. The voltage $V_{s}$ can be written as:

$$
V_{S}=\left[R_{S}\right] \cdot\left(\left(I_{S}\right)+\frac{d}{d t}\left(\Phi_{S}\right)\right.
$$

Expression of the fluxes at the rotor can be written as:

$$
V_{s d}=\left[R_{s} I_{s d}\right]+\frac{d}{d t} \Phi_{s d}-\omega_{s} . \Phi_{s q}
$$

And the relation can be written as:

$$
V_{s q}=\left[R_{s} I_{s q}\right]+\frac{d}{d t} \Phi_{s q}-\omega_{s} . \Phi_{s d}
$$

Expression of the fluxes at the stator can be written as:

$$
\begin{aligned}
& V_{s d}=\left[R_{s} I_{s d}\right]+L_{s} \frac{d}{d t} I_{s d}+M_{s r} \frac{d}{d t} I_{r d}-\omega_{s} \cdot \Phi_{s q} \\
& V_{s q}=\left[R_{s} I_{s q}\right]+L_{s} \frac{d}{d t} I_{s q}+M_{s r} \frac{d}{d t} I_{r q}+\omega_{s} \cdot \Phi_{s d}
\end{aligned}
$$

Where

$$
\begin{aligned}
& \Phi_{s d}=L_{s} \cdot I_{s d}+M_{s r} \cdot I_{r d} \\
& \Phi_{s q}=L_{s} \cdot I_{s q}+M_{s r} \cdot I_{r q}
\end{aligned}
$$

Expressions of the electromagnetic torque $\left(T_{e}\right)$ can be written as [8]:

$$
T_{e}=p \cdot \frac{M_{s r}}{L_{r}}\left(\Phi_{r d} \cdot I_{s q}+\Phi_{r q} \cdot I_{s d}\right)
$$

When $\Phi_{r q}=0$ then $\Phi_{r d}=\Phi_{r}$ then:

$$
T_{e}=p \cdot \frac{M_{s r}}{L_{r}} \Phi_{r} \cdot I_{s q}
$$

Considering that the rotor is in short-circuit from that we can get:

$$
\begin{aligned}
\Phi_{r d}^{\prime} & =\frac{M_{S r}}{1+\tau_{r} S} \cdot I_{s d} \\
\omega_{r}^{\prime} & =\frac{M_{s r}}{\left|\Phi_{r d}\right| \cdot \tau_{r}} \cdot I_{s q}
\end{aligned}
$$

Where the rotor time constant $\tau_{r}=\frac{L_{r}}{R_{r}}$.

\section{Design of an open loop indirect control}

By internal model of the Asynchronous machine, we set the currents $I_{s d}$ and $I_{s q}$ as shown in Figure (5). The rotor flux is set in an open loop as a control variable. The control signal from the PWM circuit used to control the voltage source inverter to obtain the desired speed and the desired value of electromagnetic torque which can be set by the PI controller. The speed control of the induction machine is established by controlling the stator current $I_{s d}$ and $I_{s q}$ where

- $I_{s d} *$ is used to set the flux.

- $I_{s q} *$ is used to set the torque.

By internal model of the Asynchronous machine, we set the currents $I_{s d}$ and $I_{s q}$ as shown in Fig. (6). In self-control, position sensor allows calibration of the rotor angle in relation to theta of the machine and the angular reference $(\omega \mathrm{r}=\omega \mathrm{s}-\mathrm{p} \Omega)$ where $\mathrm{p}$ is the number of pairs of poles and $\Omega$ is the rotation frequency of the motor. Figure (7) shows the results of speed, torque and stator currents for open loop 
indirect control. The circuit is designed using PSIM software for induction machine at the reference speed $=1200 \mathrm{rpm}$.

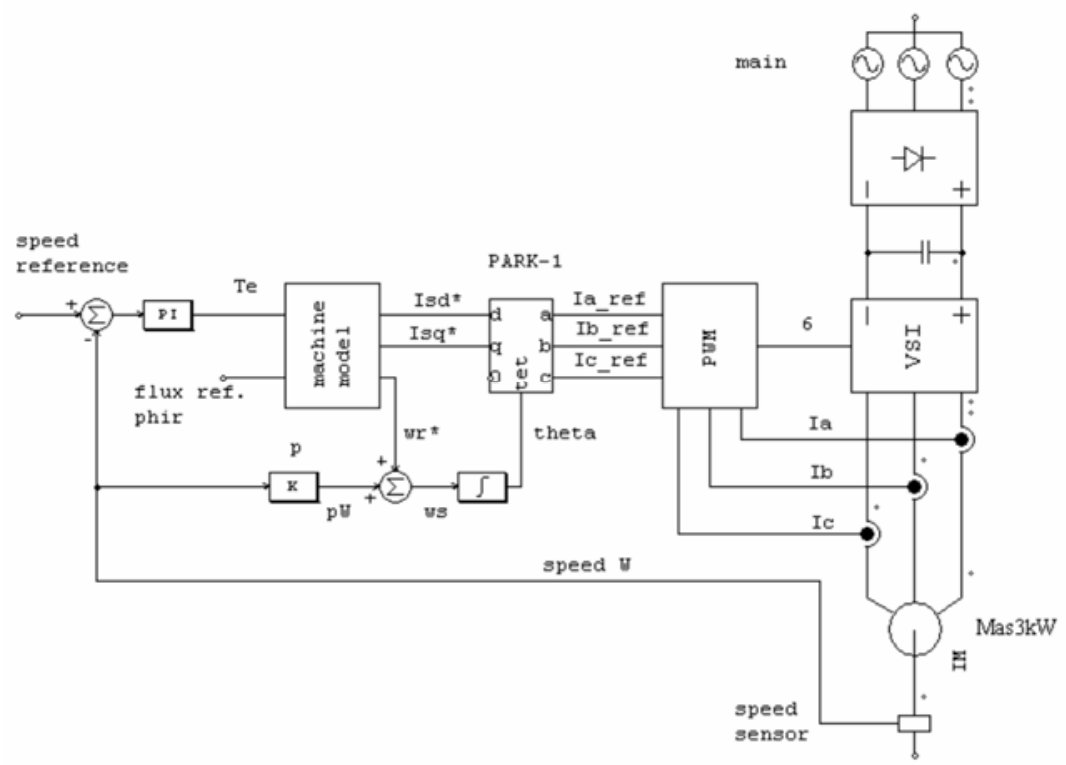

FIG. 6. DESIGN OF AN OPEN LOOP INDIRECT CONTROL.

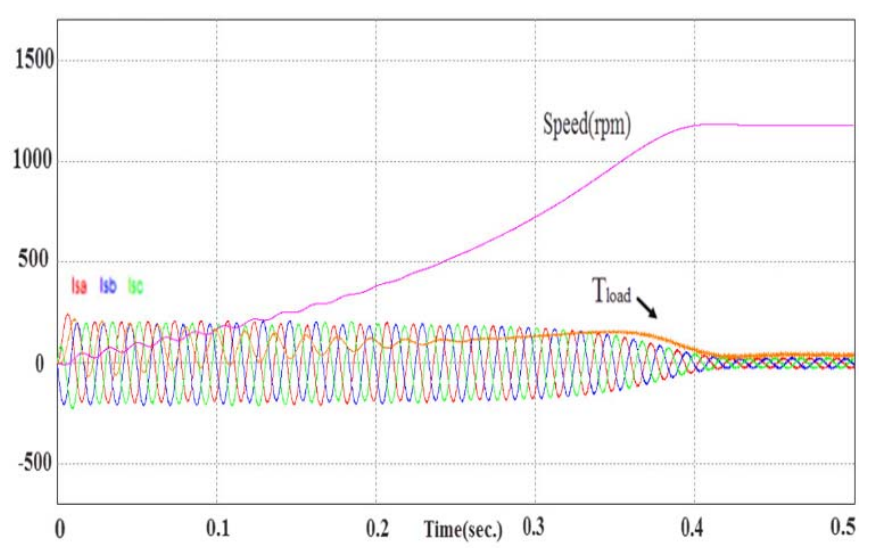

FIG. 7. THE RESULTS OF SPEED, TORQUE AND STATOR CURRENTS FOR OPEN LOOP INDIRECT CONTROL.

\section{Design of the closed loop direct control}

By canceling the flux component on the q-axis $\left(\Phi_{\mathrm{rq}}=0\right)$. Contrary to the previous case, the rotor flux is estimated (Phir*) using the equations of the machine. This estimation is then compared with a reference variable in order to set up the control system. For this type of control, it will be necessary to measure the currents to reconstruct the state variables (observer). The control signal from the PWM circuit used to control the voltage source inverter to obtain the desired speed and the desired value of electromagnetic torque [9]. Figure (8) shows the design of the closed-loop direct control.

The expressions of the voltages $V_{s d}$ and $V_{s q}$ cannot be directly used to implement the control strategy where $V_{s d}$ and $V_{s q}$ are linked (coupled) to $I_{s d}$ and $I_{s q}$. It is therefore not possible to control the torque directly by $V_{s q}$ and the flux by $V_{s d}$. Consequently, it is necessary to decouple these variables so we can control the torque with $V_{s q}$ and control the flux with $V_{s d}$ [10]. 


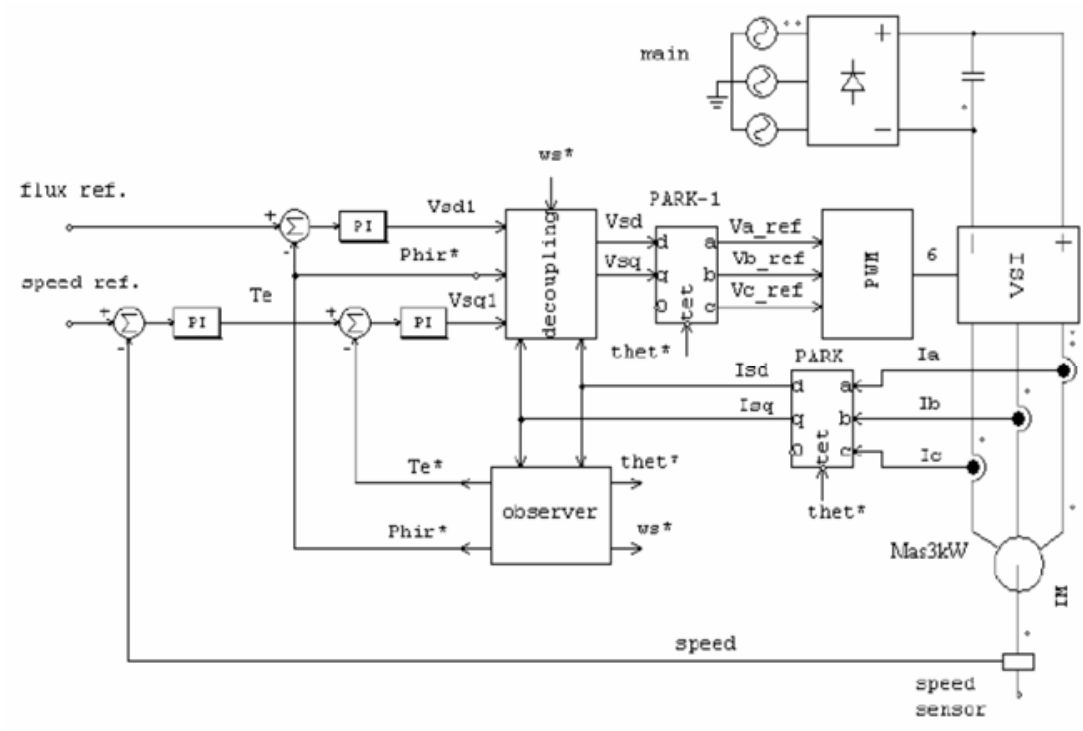

Fig. 8. DESIGN OF THE CLOSED LOOP DIRECT CONTROL.

$$
\begin{gathered}
V_{s d}=V_{s d} 1-e_{s d} \\
V_{s q}=V_{s q} 1-e_{s q} \\
e_{s d}=\omega_{s} \sigma . L_{s} I_{s q}+\frac{L_{m}}{L_{r}^{2}} R_{r} \Phi_{r} \\
e_{s q}=-\omega_{s} \sigma . L_{s} I_{s d}-\frac{L_{m}}{L_{r}} \omega_{s} \Phi_{r}+\frac{L_{m}^{2}}{L_{r} \cdot \tau_{r}} I_{s q}
\end{gathered}
$$

Figure (9) shows the simulation results of speed, torque and stator currents control with VSI drives using PSIM at the reference speed $=1200 \mathrm{rpm}$.

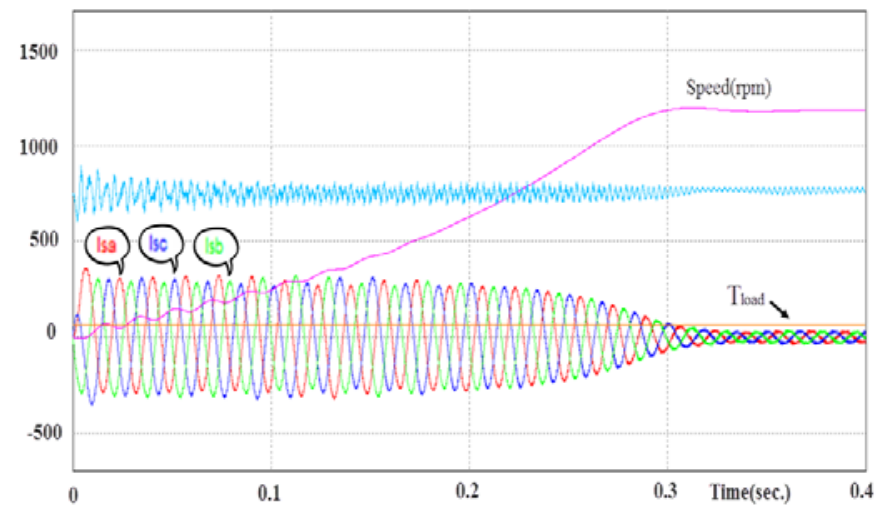

FIG. 9. SPEED, TORQUE AND STATOR CURRENTS WITH VSI DRIVES

\section{CONCLUSIONS}

From the result obtained one can find that the open loop indirect control achieves slightly good results which are always a benefit by using the independent inner current PI controllers. The speed regulation function is perfect during steady state. In a dynamic state, when there is a change of quadrant, which improved by the addition of an energy recuperation system. The design concerns the behavior of the electromagnetic torque in dynamic mode. In the closed-loop direct control, torque is controlled with Vsq and the flux is controlled with Vsd by decoupling these variables and it is improved by a current command. In the case where variations of the reference are rapid, direct command, which is more complex is more efficient. 


\section{REFERENCES}

[1] Gabriel, R., W. Leonhard, and C.J. Nordby, "Field-Oriented Control of a Standard AC Motor Using Microprocessors". IEEE transactions on industry applications, 1980(2): pp. 186-192.

[2] Kubota, H. and K. Matsuse, "Speed sensorless field-oriented control of induction motor with rotor resistance adaptation". IEEE Transactions on Industry Applications, 1994. 30(5): pp. 1219-1224.

[3] Bonnett, A.H. and G.C. Soukup, "Cause and analysis of stator and rotor failures in three-phase squirrel-cage induction motors". IEEE Transactions on Industry Applications, 1992. 28(4): pp. 921-937.

[4] David W Knight., "Solenoid inductance calculation".v 0.20, 4th Feb. 2016.

[5] Li, Y.-C. and C.-L. Chen, "A novel single-stage high-power-factor AC-to-DC LED driving circuit with leakage inductance energy recycling". IEEE Transactions on Industrial Electronics, 2012. 59(2): pp. 793-802.

[6] Abdel-Razek, A., et al., "The calculation of electromagnetic torque in saturated electric machines within combined numerical and analytical solutions of the field equations". IEEE Transactions on Magnetics, 1981. 17(6): pp. 3250-3252.

[7] Quintas, P., D. Wield, and D. Massey, "Academic-industry links and innovation: questioning the science park model". Technovation, 1992. 12(3): pp. 161-175.

[8] Hopfensperger, B., D. Atkinson, and R. Lakin, "Stator-flux-oriented control of a doubly-fed induction machine: with and without position encoder". IEE Proceedings-Electric power applications, 2000. 147(4): pp. 241-250.

[9] Fengxiang Wang, Zhenbin Zhang, Xuezhu Mei, José Rodríguez and Ralph Kennel , "Advanced Control Strategies of Induction Machine: Field Oriented Control, Direct Torque Control,and Model Predictive Control”. Energies 2018, 11, 120; doi:10.3390/en11010120, 2018.

[10] Briz, F., M.W. Degner, and R.D. Lorenz, "Analysis and design of current regulators using complex vectors". IEEE Transactions on Industry Applications, 2000. 36(3): pp. 817-825. 